\title{
MUSIK TRUNTHUNG SEBAGAI MEDIA EKSPRESI MASYARAKAT WARANGAN
}

\author{
Fajry Subhaan Syah Sinaga \\ Prodi Pengkajian Seni Pertunjukan dan Seni Rupa, Sekolah Pascasarjana, \\ Universitas Gadjah Mada Yogyakarta \\ fajry.sinaga@gmail.com
}

\begin{abstract}
Abstrak
Penelitian ini dilatarbelakangi oleh penggunaan Musik Trunthung dalam beberapa acara seperti ritual maupun kesenian yang ada dan berkembang di Dusun Warangan. Pada awalnya Trunthung berfungsi sebagai alat musik pengiring pada Tari Soreng. Dalam perkembangannya, Musik Trunthung mengalami transformasi dari musik pengiring menjadi sebuah pertunjukan musik yang mandiri. Tujuan penelitian ini adalah mengetahui peran dan pengaruh Musik Trunthung dalam kehidupan masyarakat Warangan. Pendekatan yang digunakan dalam penelitian ini adalah etnomusikologi dengan menggunakan metode kualitatif deskriptif. Hasil penelitian menunjukan bahwa Musik Trunthung merupakan media ekspresi bagi masyarakat Warangan baik digunakan sebagai pengiring dalam Tari Soreng maupun sebagai bagian dalam ritual Nyadran Kali di Dusun Warangan. Musik Trunthung juga mengalami transformasi dari peranan awalnya sebagai musik pengiring Tari Soreng menjadi sebuah pertunjukan musik yang mandiri. Musik Trunthung lahir dan tercipta tahun 2002 di Dusun Warangan atas gagasan dari Sutanto Mendut (Presiden Komunitas Lima Gunung) dan Eko Sunyoto (Seniman Sanggar Warangan Merbabu) serta kerja sama dengan masyarakat Dusun Warangan.
\end{abstract}

Kata kunci: musik trunthung, media ekspresi, ritual, transformasi, musik pengiring, pertunjukan musik.

\begin{abstract}
Trunthung music in various events, rituals, and arts in Dusun Warangan are the background of this research. Trunthung music was originally a musical acompaniment of Soreng Dance. During its development, Trunthung transformed from musical acompaniment to be an independent performing music. This research aims to know the role and effect of Trunthung music in Warangan society. The approach, used in this research, is ethnomusicology with descriptive qualitative method. The result of this research indicates that Trunthung Music is a expressive media for Warangan society, used for both as music acompaniment in Soreng dance and as a part of Nyadran Kali rituals in Dusun Warangan. Trunthung music also transformed from its first function as a musical acompaniment in Soreng Dance to be an independent perfoming music. Trunthung music was made in 2002 in Dusun Warangan by Sutanto Mendut (the president of Komunitas Lima Gunung) and Eko Sunyoto (Sanggar Warangan Merbabu artist) working together with Dusun Warangan society.
\end{abstract}

Keyword: Trunthung music, expressive media, rituals, transformation, musical acompaniment, performing music

\section{A. PENDAHULUAN}

Trunthung adalah sebuah alat musik tradisonal yang tumbuh dan berkembang di Wilayah Kabupaten Magelang. Alat musik Trunthung termasuk dalam jenis alat musik rebana atau terbangan namun memiliki bentuk yang lebih 
kecil dari rebana pada umumnya. Trunthung dimainkan dengan cara dipukul menggunakan sebilah bambu berukuran $40 \mathrm{~cm}$. Penamaan alat Musik Trunthung merupakan onomatope dari bunyi yang dihasilkan yaitu "thung", sehingga masyarakat mengenalnya sebagai alat musik Trunthung.

Pada awalnya Trunthung merupakan salah satu alat musik pengiring dalam pertunjukan Tari Soreng dan berfungsi sebagai pengatur irama (tempo) gerakan tari. Selain Trunthung, ada beberapa alat musik lainnya seperti bendhe dan bedug yang berfungsi sebagai musik pengiring Tari Soreng. Tari Soreng merupakan kesenian asli masyarakat Jawa dan termasuk dalam jenis tarian keprajuritan yang cukup berkembang di Wilayah Kabupaten Magelang. Tari Soreng merupakan kesenian yang diadopsi dari kisah Haryo Penangsang beserta prajuritnya dari Kerajaan Jipang Panolan untuk melawan Pajang di bawah pimpinan Sultan Hadi Wijoyo. Salah satu daerah yang mengembangkan kesenian Tari Soreng adalah Dusun Warangan.

Dusun Warangan secara administratif termasuk dalam wilayah Desa Muneng Warangan, Kecamatan Pakis, Kabupaten Magelang. Dusun Warangan merupakan daerah lereng gunung Merbabu yang mayoritas penduduknya adalah seorang petani. Masyarakat Dusun Warangan sebagian besar beragama Islam, namun ada beberapa orang yang menganut kepercayaan pra-islam yaitu kepercayaan terhadap hal-hal yang bersifat gaib. Menurut Handoko selaku ketua sanggar kesenian di Dusun Warangan, masyarakat masih percaya terhadap ajaran Jawa, salah satunya seperti ngelmu petung. ${ }^{1}$ Orang dapat memahami hari yang baik untuk melakukan hajatan, seperti hari baik untuk melakukan perkawinan, sunatan, penebangan pohon, maupun pesta adat. Tidak semua orang dapat menguasainya, tetapi keyakinan terhadap perhitungan ini hampir diyakini oleh semua warga. ${ }^{2}$ Beberapa ritual yang masih ada di Dusun Warangan yaitu aum tandur, aum panen, nyadran makan dan nyadran kali. Hampir semua ritual yang dilaksanakan berhubungan dengan kegiatan sehari-hari mereka seperti masa tanam, masa panen hingga rasa syukur atas mata air yang melimpah. Nyadran Kali merupakan ritual yang menjadi ciri khas Dusun Warangan, Ritual nyadran kali dilaksanakan sebagai rasa syukur atas sumber air yang melimpah untuk memenuhi pengairan di lahan pertanian hingga kebutuhan sehari-hari warga Warangan.

Kesenian merupakan syarat yang harus ada ketika ritual dilaksanakan di Dusun Warangan. Tari Soreng adalah kesenian wajib yang harus dipentaskan ketika ritual Nyadran Kali dilaksanakan setiap tahunnya. Hal ini yang mendasari Tari Soreng cukup berkembang di Dusun Warangan. Selain itu, Trunthung sebagai alat musik dalam pertunjukan Tari Soreng turut memberikan pengaruh yang besar dalam perkembangan kesenian yang ada di Dusun Warangan. Salah satunya

\footnotetext{
${ }^{1}$ Ngelmu petung adalah ilmu perhitungan hari dalam penanggalan Jawa.

2 Berdasarkan wawancara Handoko (selaku ketua sanggar kesenian Dusun Warangan) 2 Desember 2015, di Dusun Warangan.
} 
adalah lahirnya kesenian musik baru yang dikembangkan dari musik pengiring Tari Soreng dan lebih dikenal dengan nama Musik Trunthung.

Musik Trunthung adalah pertunjukan musik yang memiliki irama rampak dari perpaduan Trunthung sebagai instrumen utama dengan beberapa instrumen ritmis lain seperti rebana, bende besar dan kecil, simbal, bass drum, tambur besar dan kecil. ${ }^{3}$ Dilihat dari alat Musik Trunthung itu sendiri, yang membedakan Musik Trunthung dengan peranan awalnya sebagai musik iringan Tari Soreng terletak pada jumlah alat musiknya. Pada iringan Tari Soreng dimainkan oleh satu pemain tetapi pada Musik Trunthung konsep dalam penyajian pertunjukannya lebih kepada kolosal atau lebih dari satu orang.

Dalam perkembangannya, banyak masyarakat Warangan yang berminat untuk mempelajari Musik Trunthung. Hal ini dibuktikan dengan banyaknya masyarakat yang berpartisipasi aktif dalam setiap pertunjukan Musik Trunthung. Seiring berjalannya waktu, kesenian ini telah memberikan representasi bahwa Trunthung mempunyai nilai-nilai yang menjadi sebuah kebanggaan tersendiri bagi masyarakat dusun Warangan. Seniman yang ada di wilayah Magelang tergabung dalam komunitas seniman bernama "Komunitas Lima Gunung". Lima gunung tersebut terdiri dari Gunung Merbabu, Merapi, Sumbing, Andong, dan pegunungan Menoreh.

Kiprah para seniman gunung di kancah seni regional, nasional, hingga dunia dimulai sejak hadirnya Komunitas Lima Gunung, yang digagas sejumlah seniman di Magelang sejak tahun 2002. Melalui Festival Lima Gunung (Merapi, Merbabu, Sumbing, Andong, dan Pegunungan Menoreh), para seniman tersebut menampilkan berbagai pertunjukan seni dengan ciri khas setiap gunung. Musik Trunthung merupakan kesenian yang menjadi ciri khas Dusun Warangan.

Musik Trunthung mulai menjadi bagian dalam masyarakat Dusun Warangan dan membuat masyarakat berorientasi untuk melakukan penyesuaian terhadap Musik Trunthung. Pada mulanya, mereka memandang Musik Trunthung sebagai hal baru dengan harapan agar bisa diterima dan diakui keberadaan serta eksistensinya di tengah masyarakat, namun seiring berjalannya waktu pandangan tersebut mulai berkembang untuk melakukan modifikasi pada Musik Trunthung dan sangat berpengaruh terhadap proses perubahan Musik Trunthung.

Permainan Trunthung ketika pertama kali dipentaskan pada tahun 2002 masih menggunakan pakem ${ }^{4}$ yang terdapat dalam musik pengiring Tari Soreng. Namun dalam perkembangannya, pola permainan tabuhan dalam kesenian Trunthung mengalami perubahan karena adanya pengaruh dan kontak dengan budaya luar. ${ }^{5} \mathrm{Hal}$ tersebut terlihat pada ketukan-ketukan Trunthung yang menggunakan idiom yang

${ }^{3}$ Titi Mumfangati, "Warangan: Sebuah Dusun Sarat Seni Dan Tradisi" dalam Jurnal Jantra, Vol. II, No. 4, (Yogyakarta: Balai Pelestarian Sejarah Dan Nilai Tradisional, 2007), 268.

${ }_{4}$ Pakem dalam kamus KBBI merupakan serapan dari bahasa Jawa yang berarti cerita wayang yang asli, namun dalam hal ini berarti rangkaian musik yang asli.

R. M. Soedarsono, "Seni Pertunjukan Indonesia di Era Globalisasi", (Yogyakarta: Gadjah Mada University Press, 2010), 2. 


\section{Seminar Antarbangsa}

terdapat dalam musik populer seperti penggunaan irama dangdut dan penambahan alat musik lain seperti ketipung, gamelang, keyboard dan beberapa alat musik modern.

Musik Trunthung dilihat dari perkembangan yang telah disebutkan di atas, memberikan ketertarikan peneliti untuk menelaah lebih lanjut. Fokus dalam penelitian ini adalah penyajian Trunthung dalam ritual Nyadran Kali, penyajian Trunthung sebagai musik pengiring Tari Soreng serta penyajian Trunthung sebagai seni pertunjukan dan faktor-faktor yang mempengaruhi dalam proses perubahan Trunthung yang menjadikan Musik Trunthung sebagai media Ekspresi Masyarakat Warangan. Ekspresi tersebut terlihat baik dalam ritual maupun pertunjukan hiburan yang ada di Dusun Warangan. Perkembangan Musik Trunthung dari pertama kali dipentaskan pada Tahun 2002 hingga saat ini sangat kompleks dan tidak hanya menyangkut pada tubuh kesenian itu sendiri, melainkan dari komponen lain termasuk seniman penggarap, masyarakat pendukung, dan penikmat seni.

\section{B. MUSIK TRUNTHUNG SEBAGAI MEDIA EKSPRESI MASYARAKAT WARANGAN}

1. Trunthung dalam Ritual Nyadran Kali

Soedarsono mengemukakan bahwa setiap bentuk seni pertunjukan termasuk Musik Trunthung memiliki fungsi yang berbeda-beda dan dapat dibedakan ke dalam dua bagian secara garis besar yaitu fungsi primer dan fungsi sekunder. ${ }^{6}$ Fungsi primer merupakan fungsi yang dimiliki ketika kesenian tersebut disajikan dalam peristiwa tertentu, jelas siapa pelakunya dan siapa penikmatnya. Fungsi primer terbagi menjadi tiga bagian, yaitu (1) sebagai sarana ritual yang ditunjukan kepada penikmatnya yang berupa kekuatan yang tidak kasat mata; (2) sebagai sarana hiburan pribadi yang penikmatnya adalah masing-masing pribadi yang melibatkan diri dalam petunjukan; (3) sebagai presentasi estetis yang pertunjukannya disajikan kepada penonton atau penikmat seni.

Sementara fungsi sekunder merupakan fungsi yang dimiliki ketika kesenian tersebut ditujukan bukan sekedar untuk dinikmati, melainkan juga mempunyai kepentingan lain, di antaranya sebagai media komunikasi dan perangsang produktivitas, media ekspresi kelompok masyarakat, media meditasi dan sarana terapi, media propaganda keagamaan dan program-program pemerintah.

Nyadran Kali adalah salah satu di antara beberapa upacara tradisi yang ada di Dusun Warangan, dan uniknya hanya diselenggarakan oleh masyarakat Dusun Warangan saja. Hal ini berkaitan dengan asal mulanya tersedianya sumber air yang digunakan oleh masyarakat Warangan dan dipercaya dijaga oleh dhayang yang bernama Kanjeng Sunan Aji. Jika warga Dusun Warangan ingin memanfaatkan air maka ada beberapa persyaratan yang harus dipenuhi, antara lain mengadakan upacara adat (selamatan) setiap bulan Sapar. ${ }^{7}$ Oleh karena itu, tradisi ritual adat Nyadran Kali bertepatan dengan perhitungan kalender Jawa, pasaran Kliwon, dan

${ }^{6}$ R. M. Soedarsono, "Metodologi Seni Pertunjukan dan Seni Rupa". Bandung: Masyarakat Seni Pertunjukan Indonesia, 1999.

${ }^{7}$ Sapar adalah bulan kedua dalam penanggalan Jawa. 
setelah pertengahan bulan Sapar, sedangkan pada Tahun 2015 tradisi Nyadran Kali jatuh pada hari Rabu Kliwon tanggal 2 Desember. Dalam upacara tersebut masyarakat juga harus menyediakan sesaji berupa makanan, seperti sesaji untuk Nyadran Makam.

Penamaan Nyadran Kali adalah sesuai dengan pesan sesepuh yang mengatakan bahwa masyarakat harus mengadakan upacara nyadran seperti nyadran di makam dengan persyaratan sesaji seperti nyadran makam juga. Hal yang tidak boleh ditinggalkan adalah sesaji yang disediakan harus selalu ada ingkung ayam utuh, seperti bagian kepala, cakar serta sayapnya dibawa ke mata air, khusus untuk penunggu Mata Air Puyam yaitu Kanjeng Sunan Aji. Masyarakat Dusun Warangan meyakini, keharmonisan hubungan antara mereka yang hidup dengan roh-roh yang berada di sekitar lingkungannya akan menghasilkan ketentraman hidup. Upacara atau ritual adat dilakukan sebagai upaya untuk memperoleh ketentraman di Dusun Warangan.

Seminggu sebelum pelaksanaan Nyadran Kali, warga setempat sudah bergotong-royong untuk membersihkan bak air bersih di sumber mata air dan lingkungan sekitar Kali Puyam tersebut. Nyadran Kali dimulai pada pagi hari sekitar pukul 09.00 WIB, ditandai dengan sudah banyaknya warga yang berkumpul di sekitar halaman Sanggar Warangan Merbabu (Rumah Handoko). Puluhan warga setempat bersama para anggota Sanggar Warangan Merbabu yang mengenakan pakaian serba hitam dan kostum tarian tradisional Soreng dipimpin sesepuh warga. Mbah Jumo (selaku sesepuh di Dusun Warangan), memulai Nyadran Kali dengan berjalan kaki menyusuri jalan setapak menuju sumber mata air Puyam dengan membawa sesaji yang dipanggul dengan wadah berbentuk rumah-rumahan yang terbuat dari bambu dan dedaunan berwarna hijau sembari diiringi tabuhan suara dari alat Musik Trunthung dan bendhe yang dimainkan oleh pengurus dari Sanggar Warangan Merbabu.

Pelaksanaan Nyadran Kali tahun 2015 dihadiri oleh Kepala Bidang Kesenian dan Nilai-Nilai Tradisi Dinas Pariwisata dan Kebudayaan Pemerintah Kabupaten Magelang Achmad Husein, Sekretaris Desa Muneng Warangan Budi Santoso, dan Kepala Dusun Warangan Ismadi. Mereka juga diajak Mbah Dargo selaku sesepuh Dusun Warangan untuk berdoa dan memohon keselamatan, kelancaran, dan rejeki yang cukup melalui pekerjaan sehari-hari terutama dari hasil pertanian aneka sayuran di sekitar Dusun Warangan. Setelah selesai melakukan prosesi di Sumber Mata Air Puyam, rangkaian acara selanjutnya adalah kenduri warga di rumah Pak Ismadi selaku Kepala Dusun (Bayan) Warangan dan pementasan berbagai kesenian tradisional sebagai syarat dalam setiap ritual yang diadakan, antara lain Tari Soreng, Kubro Siswo, Warokan, Topeng Ireng, Pentas Teatrikal, Musik Eksploratif oleh Kelompok Jodokemil Magelang, dan Ketoprak.

Musik Trunthung yang dimainkan ketika mengiringi sesaji dari Dusun Warangan menuju Sumber Mata Air Puyam berfungsi untuk menarik perhatian warga dan pengunjung yang menghadiri ritual Nyadran Kali di Dusun Warangan. Hal ini dilakukan karena melihat karakteristik dari alat Musik Trunthung yang memiliki suara rampak dan dinamis jika dimainkan bersama alat musik lainnya seperti bende maupun kenthongan. Merujuk pada teori yang dikemukakan Soedarsono dalam konsteks Nyadran Kali, 
Hadirnya Musik Trunthung merupakan fungsi sekunder yang digunakan sebagai media komunikasi antara pelaku ritual dan penonton yang hadir. Hal ini tidak lepas dari alat Musik Trunthung yang digunakan sebagai pengiring dalam Tari Soreng sebagai syarat hiburan yang ditunjukan kepada penunggu Sumber Mata Air Puyam.

\section{Trunthung Pengiring}

Tari Soreng merupakan kesenian yang harus dipentaskan di depan Sumber Mata Air Puyam ketika upacara Nyadran Kali dilaksanakan, hal tersebut seperti yang diungkapkan oleh Handoko,

"Dari dulu sampai sekarang Soreng pasti pentas di acara Nyadran Kali, walaupun sekarang ini sudah berkembang beberapa kesenian, karena itu memang sudah permintaan penunggunya dari dulu. Kebetulan pada saat ditemukan Sumber Mata Air Puyam, kesenian yang ada ya cuma Soreng itu. Jadi kita hanya melanjutkan saja dari yang sudah-sudah." ${ }^{8}$

Alat musik yang digunakan sebagai pengiring dalam pementasan Tari Soreng yaitu Trunthung, Bende besar dan kecil, serta Bedug. Trunthung merupakan alat musik yang berbentuk seperti rebana namun memiliki ukuran yang kecil, ciri khas dari alat Musik Trunthung dapat dilihat pada suara yang dihasilkan, yaitu memiliki suara yang keras, rampak dan dinamik, sehingga dapat menarik perhatian penonton. Pada pertunjukan Tari Soreng, Trunthung berfungsi sebagai pengatur irama gerak dan tempo tarian. Teknik permainan Trunthung dalam Tari Soreng adalah pinatut, yaitu bermain dengan menyesuaikan gerakan dan musik.

Musik dalam tari bukan hanya sekedar iringan, hingga saat ini dapat dikatakan bahwa dimana ada tari pasti ada musik pengiringnya. Musik adalah partner tari yang tidak dapat dipisahkan. ${ }^{9}$ Dalam hal ini musik dibagi menjadi dua, yaitu musik internal dan musik eksternal. Musik internal adalah musik yang berasal dari dalam diri penari. Musik eksternal adalah musik yang berasal dari luar diri penari. Dalam kaitan dengan musik eksternal, penari tidak menari sambil memainkan musik. Penari hanya menari, sedangkan musiknya dimainkan oleh pemusik. ${ }^{10}$

Sebagai musik pengiring dalam Tari Soreng, Trunthung termasuk dalam kategori musik eksternal yang dimainkan oleh satu orang dan dipadukan dengan beberapa alat musik lainnya seperti bende dan bedug. Bende memiliki bentuk menyerupai gong dan kempul namun memiliki bentuk yang lebih kecil, alat musik ini dimainkan dengan cara dipukul secara bergantian sehingga membentuk suatu pola melodi yang berulang-ulang. Bedug berfungsi sebagai seleh pada tiap delapan ketukan terakhir untuk memberi tekanan suara rendah dan dimainkan dengan cara dipukul menggunakan sebatang kayu yang ujungnya diberi karet.

\footnotetext{
${ }^{8}$ Berdasarkan wawancara Handoko, pada tanggal 6 Maret 2016, di Sanggar Warangan Merbabu.

${ }^{9}$ R. M. Soedarsono, Tari-Tarian di Indonesia I, (Jakarta: Proyek Pengembangan Media Kebudayaan Dirjen Kebudayaan Depdikbud, 1977), 26.

${ }^{10}$ R. M. Soedarsono, 1977, 26.
} 
Tari Soreng merupakan bentuk seni pertunjukan kerakyatan karena mempunyai sifat-sifat yang dimiliki oleh seni pertunjukan rakyat pada umumnya. Salah satu sifatnya adalah kemunculan Tari Soreng dianggap sebagai suatu tradisi yang diperoleh secara turun-temurun dari generasi ke generasi berikutnya. Pada saat musik maupun tarian diciptakan, masyarakat segera mengklaim menjadi miliknya sebagai suatu ekspresi kolektif. Maka dari itu, tidak heran jika pencipta suatu seni pertunjukan kerakyatan adalah anonim. ${ }^{11}$

Alat Musik Trunthung telah melekat dan menjadi ciri khas bagi wilayah lereng Merbabu dan Kabupaten Magelang. Asal-usul atau sejarah alat Musik Trunthung hadir di wilayah lereng Merbabu khusunya di Dusun Warangan belum begitu jelas, karena tidak ada sumber data jelas yang menyebutkan kapan dan dimana alat Musik Trunthung ada untuk pertama kalinya. Namun, jika melihat pada kesenian tradisional yang tumbuh di Dusun Warangan sekitar tahun 1960-an dan perkembangan Kesenian Soreng di Warangan sekitar tahun 1974-an, dapat diperkirakan sebelum tahun 1960-an alat Musik Trunthung sudah ada dan digunakan sebagai alat musik pengiring dalam pertunjukan Tari Soreng di Dusun Warangan.

\section{Trunthung sebagai Sajian Pertunjukan}

Kesenian Trunthung muncul pertama kali sebagai sajian musik yang mandiri pada tahun 2002 di Dusun Warangan Kecamatan Pakis Kabupaten Magelang yang dipelopori oleh Eko Sunyoto dan Sutanto Mendut. Mereka berdua menggarap Trunthung untuk pertama kali menjadi sebuah sajian pertunjukan kolosal yang dimainkan oleh 80 orang ketika mengikuti gelar nasional dan pembukaan Galeri Langgeng Kabupaten Magelang. Sutanto Mendut dalam pidato pembukaan Galeri Langgeng sekaligus pentas perdana Kesenian Trunthung, mengatakan bahwa:

"Saya baru berteman dengan teman-teman Merbabu sekitar 2-3 tahun yang lalu yaitu pada tahun 2000, pertunjukan ini adalah sebuah gubahan yang direncakan selama 1 bulan terakhir. Secara tradisi Trunthung hanya dimainkan oleh satu orang dan empat bende, kemudian saya iseng-iseng bagaimana jika Trunthung dimainkan oleh 40 atau 30 pemain. Mereka setuju tapi coba dibuktikan senang atau tidak ketika memainkannya."12

Setelah pidato pembukaan yang disampaikan oleh Sutanto Mendut, pentas dimulai dengan diawali permainan piano dari Sutanto Mendut, disusul permainan Trunthung dari para pemain yang sudah siap di atas panggung. Pada pertengahan pertunjukan para pemusik membagikan kenthongan kepada penonton dan mengajak mereka untuk bergabung dalam pertunjukan dengan cara memukul kenthongan tersebut.

${ }^{11} \mathrm{Rr}$. Paramitha Dyah Fitriasari, Bentuk dan Fungsi Kesenian Rakyat Topeng Ireng Desa Warangan Kecamatan Pakis Kabupaten Magelang Jawa Tengah, (Yogyakarta: Universitas Gadjah Mada, 2008), 62.

Berdasarkan video dokumentasi pementasan perdana Musik Trunthung dalam pembukaan Galeri Langgeng Magelang pada tahun 2002. 


\section{Seminar Antarbangsa}

Penulis akan mencoba menganalisis bentuk penyajian Trunthung ketika dipentaskan pertama kali menggunakan konsep teori dari Jeff Todd Titon tentang unsur-unsur dalam penyajian seni pertunjukan yang akan dibahas secara garis besar berupa gaya (style) dan genre. ${ }^{13}$ Gaya adalah segala sesuatu yang berhubungan dengan kesenian Trunthung, termasuk alat musik yang digunakan dalam kesenian Trunthung yang disajikan sebagai pertunjukan musik serta warna suara yang dihasilkan oleh masing-masing alat musik. Genre adalah jenis aliran musik yang dibawakan oleh kelompok kesenian ketika membawakan suatu repertoar lagu.

a. Gaya (style)

Gaya adalah segala sesuatu yang berhubungan dengan kesenian Trunthung kaitannya dengan sistem nada dan warna suara (timbre) dari alat musik yang digunakan. Kesenian Trunthung menggunakan beberapa alat musik di samping alat musik Trunthung itu sendiri sebagai alat musik utamanya, yaitu bende, bedug, bass drum dan simbal.

\section{Trunthung}

Trunthung adalah alat musik terbangan berbentuk kecil dengan diameter sekitar $15-25 \mathrm{~cm}$. Trunthung termasuk dalam keluarga membranophone yang terbuat dari kulit kambing atau sapi. Trunthung dimainkan dengan cara dipukul menggunakan sebilah bambu yang berukuran panjang sekitar $40 \mathrm{~cm}$.

Suara yang dihasilkan oleh alat Musik Trunthung adalah "thek" dan "dheng". Teknik permainan untuk menghasilkan suara tersebut yaitu dengan menekan atau melepas (mengangkat) ibu jari yang memegang membran alat musik Trunthung. Ketika ibu jari menekan permukaan membran instrumen, maka suara yang dihasilkan berbunyi "thek", sedangkan ketika ibu jari dilepaskan atau diangkat dari membran instrumen maka suara yang dihasilkan berbunyi "dheng".

Dalam penyajiannya, jumlah alat Musik Trunthung yang digunakan bisa bervariasi, rata-rata berjumlah 25-50 buah instrumen. Ketika pementasan perdananya Kesenian Trunthung dimainkan oleh 80 orang pemain. Inti dari Kesenian Trunthung yaitu dimainkan secara kolosal, namun jika diperlukan bisa dilakukan penambahan ataupun pengurangan jumlah alat musik yang digunakan.

Alat Musik Trunthung berfungsi sebagai pengatur sajian lagu. Dalam pertunjukannya, pola tabuhan alat Musik Trunthung dimainkan secara unisono atau satu suara. Pergantian pola tabuhan Trunthung adalah tanda kepada instrumen bende untuk melakukan peralihan pola tabuhan melodi. Fokus permainan pola tabuhan terletak pada instrumen Trunthung. Jika terjadi kesalahan dalam pola tabuhan Trunthung, maka akan terjadi salah tafsir secara musikal dari permainan instrumen lain yang menyebabkan rusaknya sajian musiknya. Berikut salah satu pola pada permainan Trunthung:

${ }^{13}$ Jeff Tood Titon, "The Music Culture as A World of Music" dalam Schirmer Book, Worlds of Music: An Introduction to The Music of The World's Peoples Fifth Edition, (USA: Schirmer Cengage Learning, 2009), 26. 


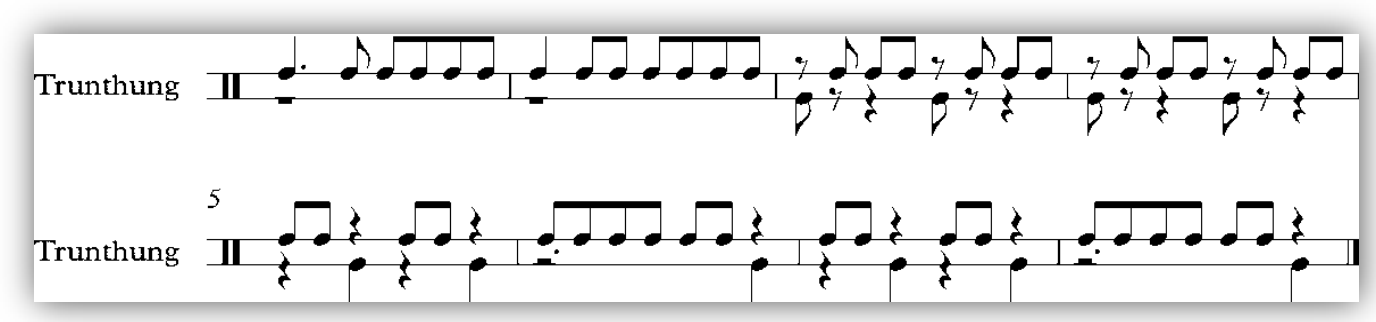

Notasi 1. Pola Permainan Musik Trunthung

Keterangan:

$>$ baris atas berbunyi "thek"

$>$ baris bawah berbunyi "dheng"

\section{Bende}

Bende adalah alat musik yang berbentuk seperti gong, dengan ukuran sekitar 30-35 cm dan terbuat dari besi. Bende dimainkan dengan cara dipukul menggunakan alat pemukul yang terbuat dari kayu berukuran panjang $15-20 \mathrm{~cm}$. Pada salah satu ujung pemukulnya dilapisi dengan bantalan yang terbuat dari kain atau karet.

Jumlah bende dalam sajian Kesenian Trunthung sebanyak 4 buah, namun jika bende yang digunakan lebih dari 4 buah, maka jumlah alat musik tersebut tetap dalam kelipatan $4(8,12$, dst). Pemakaian bende yang berjumlah lebih dari 4 dapat dilakukan jika pementasan dilaksanakan pada ruangan terbuka yang luas seperti lapangan tanpa menggunakan alat pengeras suara atau sound system.

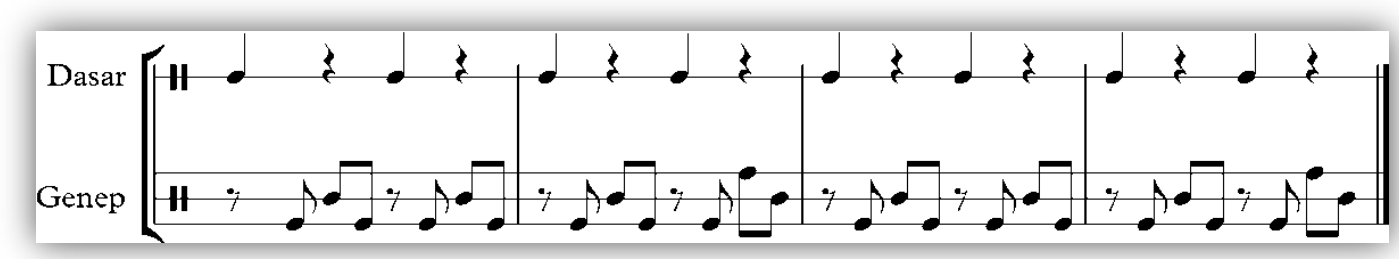

Notasi 2. Pola Permainan Bendhe

Keterangan:

$>$ baris atas merupakan dasar berbunyi "dheng"

$>$ baris bawah merupakan genep berbunyi "thung" "thang" "tang"

Dalam pertunjukan Kesenian Trunthung, bende berfungsi sebagai alat musik melodis yang dimainkan dengan teknik interlocking ${ }^{14}$ antara satu bende dengan bende lainnya. Perpaduan melodi tersebut akan membentuk pola tabuhan yang menjadi acuan permainan alat musik Trunthung. Pergantian pola melodi dilakukan dengan mengisi.

${ }^{14}$ Pola permainan antara pola dasar dengan pola pecahan, terdapat motif yang saling 


\section{Seminar Antarbangsa}

tanda yang diberikan oleh instrumen Trunthung. Permainan bende tersebut yang nantinya akan membentuk struktur dari pertunjukan Trunthung.

\section{Bedug, Bass Drum dan Simbal}

Bedug memiliki bentuk seperti kendang, dengan membran yang terbuat dari kulit sapi namun hanya terpasang pada salah satu sisi saja, sedangkan sisi lainnya terbuka. Hal ini dimaksudkan supaya suara yang dihasilkan bedug lebih keras. Namun dalam perkembangannya penggunaan alat musik bedug seringkali diganti dengan alat musik sejenis tom drum dengan membran yang terbuat dari plastik mika. Menurut Handoko tom drum dipilih karena karakter suara yang dihasilkan hampir sama seperti bedug yang terbuat dari membran kulit. Selain itu, tom drum juga mudah didapat dan memiliki berat yang lebih ringan sehingga sangat mudah untuk dibawa-bawa.

Bass Drum merupakan alat musik yang terbuat dari kayu multiplex, dengan ukuran diameter 1 meter dan panjang tabung resonansinya sekitar $40 \mathrm{~cm}$. Pada masing-masing sisinya terdapat membran yang terbuat dari plastik mika. Bass Drum dimainkan dengan cara dipukul menggunakan stik drum dengan balutan busa tebal pada salah satu ujungnya.

Alat musik Simbal terbuat dari tembaga dan memiliki ukuran diameter sekitar $35 \mathrm{~cm}$. Simbal diletakan pada sebuah stand atau tiang kaki yang terbuat dari besi dengan tinggi 1 meter. Simbal biasanya dimainkan bersama dengan bass drum untuk memberikan ketukan berat atau aksentuasi. Selain itu, ketiga alat musik diatas (bedug, bass drum, dan simbal) berfungsi sebagai pemberi tanda ketika terjadi peralihan atau perpindahan pola permainan trunthung dan bende.

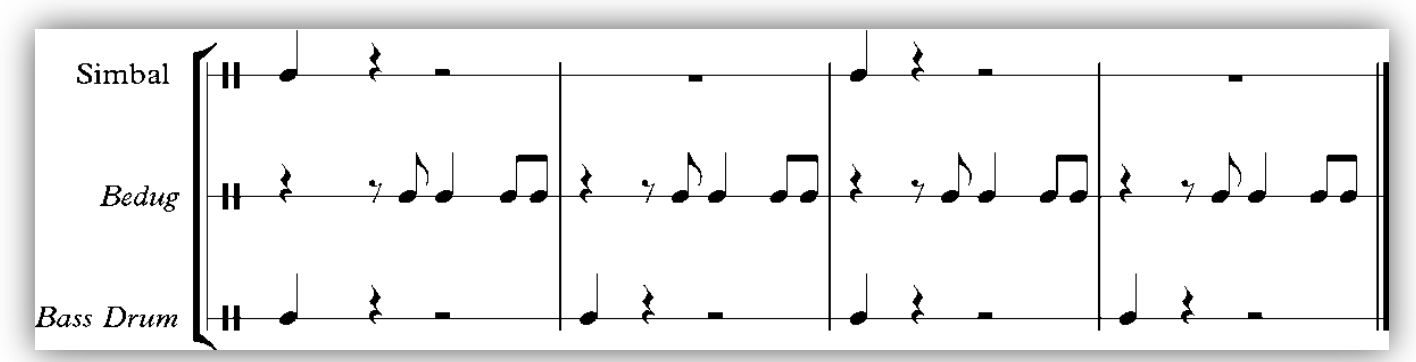

Notasi 3. Salah satu Pola Permainan Bass Drum, Bedug, dan Simbal

Keterangan:

$>$ baris pertama berbunyi "ces"

$>$ baris kedua berbunyi "dung"

$>$ baris bawah berbunyi "deng"

\section{b. Genre}

Genre berkaitan dengan jenis aliran musik yang dibawakan oleh kelompok kesenian ketika membawakan suatu repertoar lagu. Kelompok dalam konteks ini adalah para pelaku seni yang tergabung dalam Sanggar Warangan Merbabu ketika 
mementaskan Kesenian Trunthung untuk pertama kalinya dalam pembukaan Galeri Langgeng di Magelang.

Musik tradisional adalah musik yang tumbuh dan berkembang di suatu daerah tertentu dan diwariskan secara turun temurun dari satu generasi ke generasi berikutnya. ${ }^{15}$ Musik ini menggunakan bahasa, gaya, dan tradisi khas daerah setempat. Secara umum, musik tradisional memiliki ciri khas sebagai berikut: ${ }^{16}$

1. Dipelajari Secara Lisan

Proses pembelajaran dilakukan secara lisan, hal tersebut dikuatkan dengan tradisi bangsa timur (Indonesia) yang merupakan tradisi lisan. Hal ini berbeda dengan budaya barat yang dalam pembelajaran suatu kesenian menggunakan partitur (naskah musik) menjadi suatu hal yang penting. Generasi tua mengajarkan komposisi musik daerah kepada generasi muda. Anak-anak itu akan meneruskannya pula kepada anakanak mereka. Demikian seterusnya, sehingga tradisi musik tersebut tetap dikenal oleh masyarakat.

2. Tidak Memiliki Notasi

Ada beberapa daerah yang memiliki notasi musik seperti di Pulau Jawa dan Bali. Namun, notasi ini tetap tidak memiliki partitur, tapi dipelajari secara lisan. Sebenarnya, hal ini dikemudian hari dapat menimbulkan masalah. Jika orang-orang yang belajar tentang kesenian itu semakin sedikit atau malah tidak ada, kesenian tersebut bisa punah. Tanpa catatan tertulis, orang lain tidak bisa melestarikannya.

3. Bersifat Informal

Musik Tradisional sangat lazim digunakan sebagai suatu bentuk ekspresi masyarakat. Musik ini banyak digunakan dalam kegiatan rakyat biasa sehingga bersifat lebih sederhana dan informal/santai.

4. Pemainnya Tidak Terspesialisasi

Sistem yang dikembangkan dalam proses belajar instrumen musik daerah biasanya bersifat generalisasi. Pemain musik tradisional belajar untuk dapat memainkan setiap instrumen yang ada dalam suatu jenis musik daerah. Mereka akan belajar memainkan instrumen mulai dari yang termudah sampai yang terumit. Jadi, pemain musik daerah yang sudah mahir mempunyai kemampuan untuk memainkan semua instrumen musik tersebut.

5. Syair Lagu Berbahasa Daerah

Selain syair yang menggunakan bahasa daerah, musik tradisional juga menggunakan alunan melodi dan irama yang menunjukkan ciri khas kedaerahan. Misalnya, syair lagu dari daerah Jawa. Alunan melodinya pun menggunakan nadanada dari tangga nada pelog dan slendro.

6. Lebih Melibatkan Alat Musik Daerah

Umumnya, permainan musik dalam lagu-lagu daerah di Indonesia dibawakan dengan alat-alat musik khas dari daerah-daerah itu sendiri.

15 Theresiana Ani Larasati, "Kesenian Tradisional Kenthongan Wahana Remaja dan pemuda Purbalingga Mencintai Kesenian Rakyat" dalam Jurnal Jantra Vol. VII, No. 2, Desember 2012, (Yogyakarta: Balai Pelestarian Nilai Budaya Yogyakarta, 2012), 155.

https://pendidikansenibudaya.wordpress.com/2011/06/27/pengertian-musik-tradisional/, diakses pada tanggal 20 April 2016. 


\section{Seminar Antarbangsa}

\section{Merupakan Bagian dari Budaya Masyarakat}

Musik tradisional merupakan salah satu bentuk kebudayaan yang berkembang di dalam kehidupan masyarakat. Oleh karena itu, setiap ciri kebudayaan masyarakat Sang Penciptanya pasti sudah melekat erat didalamnya. Musik daerah merupakan salah satu bentuk gambaran kebudayaan suatu daerah, selain tarian, pakaian, dan adat kebiasaan lainnya. Melalui musik daerah, kita dapat mengenali daerah asal musik itu dan ciri budaya masyarakatnya.

Merujuk pada ciri-ciri diatas, Musik Trunthung dapat disebut sebagai jenis musik tradisional. Musik Trunthung dipelajari secara lisan, hal ini dibuktikan dengan tidak adanya partiture baik ketika proses latihan maupun ketika pertunjukan. Rangkaian melodi yang dimainkan sederhana dan membentuk suatu pola yang berulang-ulang, bahkan tidak heran jika melodi yang tercipta memiliki kekuatan magis tersendiri bagi para pelaku Musik Trunthung. Para pemain kesenian Trunthung merupakan warga Dusun Warangan yang tergabung dalam Sanggar Warangan Merbabu, dan hampir setiap pemain musik dapat memainkan seluruh alat yang ada pada kesenian Trunthung seperti bende, bedug, bass drum dan simbal. Alat Musik Trunthung sudah menjadi bagian masyarakat Warangan, karena hampir setiap acara yang dilaksanakan melibatkan alat Musik Trunthung baik sebagai arak-arakan, pengiring sebuah tarian, pertunjukan musik, hingga syarat dalam suatu ritual.

\section{PENUTUP}

Trunthung adalah sebuah alat musik tradisonal yang tumbuh dan berkembang di Wilayah Kabupaten Magelang. Alat Musik Trunthung termasuk dalam jenis alat musik rebana atau terbangan namun memiliki bentuk yang lebih kecil dari rebana pada umumnya. Trunthung dimainkan dengan cara dipukul menggunakan sebilah bambu berukuran $40 \mathrm{~cm}$. Penamaan alat musik Trunthung merupakan onomatope dari bunyi yang dihasilkan yaitu "thung", sehingga masyarakat mengenalnya dengan nama Trunthung.

Warangan merupakan dusun yang syarat seni dan tradisi, hal ini berkaitan dengan kehidupan masyarakat Warangan yang termasuk daerah agraris. Banyak ritual yang masih diadakan setiap tahunnya, seperti aum tandur, aum panen, nyadran makan dan nyadran kali. Semua ritual yang dilaksanakan hampir semuanya berhubungan dengan kehidupan sehari-hari penduduk Warangan seperti ritual yang diadakan pada masa tanam, masa panen, hingga ritual yang diadakan sebagai rasa syukur atas sumber air bersih yang melimpah.

Nyadran Kali merupakan ritual yang dilaksanakan sebagai rasa syukur atas sumber air yang melimpah di Dusun Warangan. Hal ini berkaitan dengan sumber mata air Puyam sebagai sumber air untuk memenuhi kebutuhan masyarakat Warangan baik untuk pengairan lahan pertanian maupun memenuhi kebutuhan sehari-hari. Beberapa fakta yang menarik lainnya adalah Sumber Mata Air Puyam hanya dapat mengalir ke Dusun Warangan. Maka dari itu, masyarakat Warangan mengadakan ritual Nyadran Kali sebagai rasa syukur atas berkah yang diberikan melalui Sumber Mata Air Puyam. 
Kesenian merupakan syarat yang harus ada dalam setiap ritual yang dilaksanakan di Dusun Warangan. Tari Soreng merupakan salah satu syarat kesenian yang harus ada dan ditampilkan ketika ritual Nyadran Kali dilaksanakan setiap tahunnya. Sehingga tidak heran jika aktvitas berkesenian yang ada di Dusun Warangan sangat berkembang. Tidak hanya Tari Soreng, alat musik Trunthung sebagai musik pengiring dalam Tari Soreng turut serta berkembang.

Pada awalnya Trunthung merupakan alat musik pengiring yang digunakan dalam pertunjukan Tari Soreng yang dipadukan dengan beberapa alat musik pengiring lainnya seperti bende dan bedug. Dalam perkembangannya Musik Trunthung berubah menjadi seni pertunjukan yang mandiri pada tahun 2002 atas gagasan ide dari Eko Sunyoto dan Sutanto Mendut. Mereka berdua menggarap Trunthung untuk pertama kali menjadi sebuah sajian pertunjukan kolosal yang dimainkan oleh 80 orang ketika mengikuti gelar nasional dan pembukaan Galeri Langgeng Kabupaten Magelang.

Perkembangan Musik Trunthung di Dusun Warangan dan Wilayah Magelang tidak lepas dari komunitas seniman lima gunung (merbabu, merapi, andong, sumbing, dan pegunungan menoreh) yang mengadakan Festival Lima Gunung setiap tahunnya sejak tahun 2002. Dimana dalam festival tersebut seniman gunung menampilkan beberapa kesenian yang menjadi ciri khas pada masing-masing daerah. Musik Trunthung adalah kesenian yang berasal dari Warangan dan menjadikan ciri khas bagi Dusun Warangan. Tidak heran jika Musik Trunthung dijadikan sebagai media ekspresi masyarakat Warangan, baik sebagai bagian dalam ritual Nyadran Kali, pengiring dalam Tari Soreng, hingga menjadi sebuah pertunjukan musik yang menjadi kebanggan bagi Masyarakat Warangan. 


\section{DAFTAR PUSTAKA}

Fitriasari, Rr. Paramitha Dyah. 2008. Bentuk dan Fungsi Kesenian Rakyat Topeng Ireng Desa Warangan Kecamatan Pakis Kabupaten Magelang Jawa Tengah. Yogyakarta: Universitas Gadjah Mada.

Larasati, Theresiana Ani. 2012. "Kesenian Tradisional Kenthongan Wahana Remaja dan Pemuda Purbalingga Mencintai Kesenian Rakyat" dalam Jurnal Jantra Vol. VII, No. 2. Yogyakarta: Balai Pelestarian Nilai Budaya Yogyakarta.

Mumfangati, Titi. 2007. "Warangan: Sebuah Dusun Sarat Seni Dan Tradisi" dalam Jurnal Jantra, Vol. II, No. 4. Yogyakarta: Balai Pelestarian Sejarah Dan Nilai Tradisional.

Soedarsono, R. M. 1977. Tari-Tarian di Indonesia I. Jakarta: Proyek Pengembangan Media Kebudayaan Dirjen Kebudayaan Depdikbud.

Soedarsono, R. M. 1999. Metodologi Seni Pertunjukan dan Seni Rupa. Bandung: Masyarakat Seni Pertunjukan Indonesia.

Soedarsono, R. M. 2010. Seni Pertunjukan Indonesia di Era Globalisasi. Yogyakarta: Gadjah Mada University Press.

Titon, Jeff Tood. 2009. "The Music Culture as A World of Music" dalam Schirmer Book. Worlds of Music: An Introduction to The Music of The World's Peoples (Fifth Edition). USA: Schirmer Cengage Learning.

\section{WEBTOGRAFI}

https://pendidikansenibudaya.wordpress.com/2011/06/27/pengertian-musiktradisional/, diakses pada tanggal 20 April 2016.

\section{NARASUMBER}

Handoko sebagai seniman penggarap Trunthung dan Ketua Sanggar Seni di Dusun Warangan. 